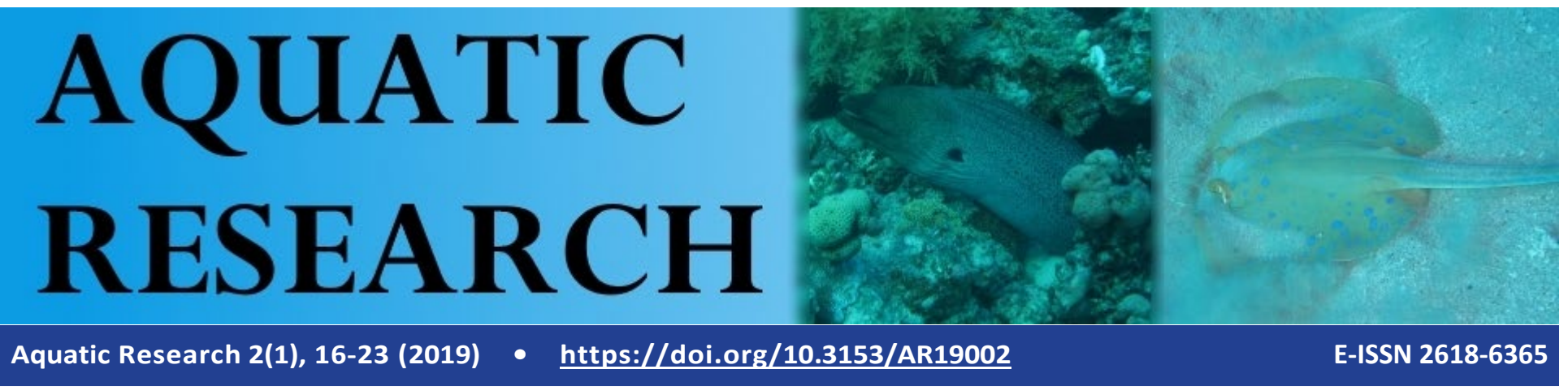

Research Article

\title{
CHANGES IN CERTAIN ACUTE PHASE PROTEINS OF COMMON CARP (Cyprinus carpio) EXPOSED TO ORGANOPHOSPHATE INSECTICIDES
}

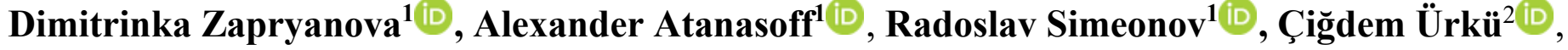 \\ Galin Nikolov $^{3}$ (D), Teodora Georgieva ${ }^{1}$ (D)
}

Cite this article as:

Zapryanova, D., Atanasoff, A., Simeonov, R., Urku, Ç., Nikolov, G., Georgieva, T. (2019). Changes in certain acute phase proteins of common carp (Cyprinus carpio) exposed to organophosphate insecticides. Aquatic Research, 2(1), 16-23. https://doi.org/10.3153/AR19002

\footnotetext{
1 Trakia University, Faculty of Veterinary Medicine, Stara Zagora, Bulgaria

2 İstanbul University, Faculty of Aquatic Sciences, İstanbul, Turkey
}

Submitted: 20.11 .2018

Accepted: 23.12 .2018

Published online: 27.12.2018

Correspondence:

Dimitrinka ZAPRYANOVA

E-mail: zaprianowa@abv.bg

๑Copyright 2019 by ScientificWebJournals

Available online at

http://aquatres.scientificwebjournals.com

\begin{abstract}
The acute phase response (APR) is a nonspecific reaction of fish to disturbances in homeostasis. The aim of present study was to investigate quantitative changes that occur in the concentration of acute phase proteins (APPs) in the blood of commercial size common carp (Cyprinus carpio L.) exposed to organophosphate insecticides within the month of April during ameliorative activities. Parameters examined were fibrinogen (Fib), ceruloplasmin (Cp) as a positive APPs and albumin (Alb) as a negative APP. Histological sections of the hepatopancreas and kidneys from 25 fish have been examined. The hepatopancreas was chosen for this investigation as it is the primary site of acute phase protein synthesis. APP parameters plasma fibrinogen $(P<0.05)$ registered a significantly increased and albumin $(P<0.05)$ exhibited statistically declined in treated group. Based on the data acquired in this study, it was concluded that, the carp do not exhibit a strong APP synthesis during the early stages of an APR after spraying with organophosphate insecticides. The results from this study show that the concentrations of fibrinogen are not significantly increase as well as the levels of ceruloplasmin remained unchanged.
\end{abstract}

Keywords: Acute phase proteins, Albumin, Ceruloplasmin, Common carp, Fibrinogen 


\section{Introduction}

The lack of sufficient data for the reference values of the biochemical parameters (including APPs) could be the reason that they are not frequently used in routine practice in the determination of blood indices in poikilothermic animals. Once established the values of these acute phase proteins can be used to assess the state of fish stress response, tissue damage or metabolic disturbances (Koynarski et al., 2018). The acute phase proteins (APPs) are reactants synthesized during an acute phase response (APR). The synthesis and role of APPs may differ depending on the animal species. The APPs whose circulating concentrations increase during APR are called positive (e.g. fibrinogen, ceruloplasmin, C-reactive protein etc.), and proteins whose concentrations decrease are called negative (e.g. albumin, transferrin) (Cray, 2013).

However, there is not enough information on the progress of the APR in the common carp after short-term exposure to organophosphate insecticides in the literature available to us.

Fibrinogen (Fib) is an APP, a $\beta$-globulin, present in the plasma of all vertebrates, which is also produced in the liver (Ceron et al., 2005). Fibrinogen is involved in homeostasis, providing a substrate for fibrin formation, and in tissue repair, providing a matrix for the migration of inflammatoryrelated cells (Tothova et al., 2011).

Ceruloplasmin (Cp), alfa 2 glycoprotein, has molecular weight of about $132000 \mathrm{D}$ and binds 6 copper ions. The copper-Cp complex is secreted by the liver into the plasma and can contribute copper to cells. $\mathrm{Cp}$ is a the acute phase protein, playing important anti-inflammatory roles, as a copper transporter from hepatocytes to other tissues, inhibits the peroxidation of membrane lipids and it is a scavenger of free radicals and superoxide. It protects polyunsaturated fatty acids in red blood cell membranes from active oxygen radicals (Yonar et al., 2010). Cp has been found in several fish species, including common carp (Cyprinus carpio), European plaice (Pleuronectes platessa), tilapia (Oreochromis niloticus), grey mullet (Mugil cephalus) and European eel (Anguilla anguilla) (Di Giulio and Meyer, 2008).

Albumin is the major negative APP in all species. The serum albumins are found not in all fish (Andreeva, 2010). Its main function is the regulation of the colloidal osmotic pressure of the blood and the transport of some endogenous and exogenous compounds.

Contamination of water by insecticides is mainly due to intensive agriculture combined with surface runoff and subsurface drainage, usually within a few weeks after application. In fish, different insecticides can be absorbed through gills, skin or alimentary ducts (Banaee, 2013). Hence, pollutants such as organophosphate insecticides (OPs) may significantly damage certain physiological and biochemical processes when they enter into the organs of fishes (Nagaraju and Rathnamma, 2013). OPs impair the enzymatic pathways involved in metabolism of carbohydrates, fats and protein within cytoplasm, mitochondria, and proxisomes. It is believed that OPs exhibit this effect through inhibition of acetylcholinesterase (AchE) or affecting target organs directly. OPs induce cellular oxidative stress via affecting mitochondrial function and therefore disrupt neuronal and hormonal status of the body (Karami-Mohajeri and Abdollahi, 2011).

The present study has been undertaken to understand the alterations occurring in blood circulating proteins, i.e. fibrinogen and ceruloplasmin (as positive APPs) and albumin as a negative APP and to evaluate their potential value as early sensitive biomarkers in common carp induced by ameliorative activities on exposure to organophosphate insecticides. The used insecticide is combined organophosphate-pyrethroid (chlorpyrifos and cypermethrin).

\section{Material and Methods}

The fish samples were obtained from the Tundzha River near the city Nikolaevo, Bulgaria. The region was chosen because of the agricultural activities of the district. One hundred thirty-seven common carp fish samples, were taken twice and transported in a conveying tank, reinforced with oxygen to the Animal Veterinary Hospital of Trakia University, Stara Zagora, Bulgaria. The first sample was obtained as part of regular monitoring (control sample), and the second sample was taken outside of schedule because of suspicion of possible organophosphate use in the neighboring agricultural lands (suspect sample). A number of changes were observed in the behaviour of fish exposed to OPs within the month of April. After arriving at the Animal Veterinary Hospital the fish were electro-anesthetized by subjected to an electrical current (DC) with high voltage $(\sim 300 \mathrm{~V})$, low capacitance $(47 \mu \mathrm{F})$ and low amperage $(4.7 \mathrm{~mA})$ for $3 \mathrm{~s}$. Out of water, fish handling and blood samples were taking by wearing latex gloves to minimize damage to the skin, mucus covering and delicate piscine cuticle. Blood was drawn from the vena caudalis using a needle $(18 \mathrm{G})$ in container with heparin as anticoagulant. The blood was collected (2.5-3.0 $\mathrm{ml}$ ) in Eppendorff vials and centrifuged at $2500 \mathrm{rpm}$ for 15 min (Janetzki T30, Germany). Plasma was immediately separated and stored at $-20^{\circ} \mathrm{C}$ until analysis.

The concentration of fibrinogen was estimated by nephelometric determination. Manual method for ceruloplasmin determination based on the oxidation of different compounds 
has become widely adopted for routine use in clinical chemistry laboratories. The Ravin's method described by Bestujeva and Kolb, (1982) is based on the in vitro oxidase activity that ceruloplasmin shows with substances such as p-phenylenediamine (PPD). A colored oxidation product is formed from the oxidation of $\mathrm{p}$-phenylendiamine by $\mathrm{Cp}$. The $\mathrm{Cp}$ activity was measured colorimetrically at $\lambda=$ $530 \mathrm{~nm}$ using Spekol Spectrocolorimeter (Spekol 11, CarlZeiss Jena, Germany). The concentrations of albumin were determined by a kit (Giesse, Diagnostics, Italy) on a SemiAuto Chemistry Analyzer (Mindray BA-88, Mindray BioMedical Electronics, Shenzhen, China).

After that fish were sacrificed by decapitation, and organs (hepatopancreas and kidney) were collected, body weight and length were measured $(1529.3 \pm 15.2 \mathrm{~g}$ and $49.5 \pm 2.3$ $\mathrm{cm})$ and prepared for histopathological analysis. The specimens for histopathological examination were fixed in 10\% neutral formalin and processed routinely. The $4 \mu \mathrm{m}$ cross sections were stained with haematoxylin-eosin.

The statistical analysis was performed using one-way analysis of variance (ANOVA). The results were processed with software Statistica v.6.1 (StatSoft Inc., 2002). All results are presented as mean and standard error of the mean (Mean \pm SEM). The statistical significance of parameters was determined in the LSD test at $\mathrm{P}<0.05$.

\section{Results and Discussion}

The changes in the concentrations of the studied acute phase proteins in the present study are shown in Table 1. The blood concentrations of fibrinogen were slightly influenced by pesticide effect. In control group the Fib levels were 1.23 $\pm 0.05 \mathrm{~g} / \mathrm{L}$ but suspected fishes showed significant differences $(P<0.05)$ and slightly elevation $-1.54 \pm 0.06 \mathrm{~g} / \mathrm{L}$. Another positive APP which was examined - ceruloplasmin, remained unchanged in both groups. In control common carp the $\mathrm{Cp}$ values were $28.22 \pm 2.09 \mathrm{mg} / \mathrm{L}$ and in the other group, the concentrations were the same $-28.87 \pm 2.49$ $\mathrm{mg} / \mathrm{L}$. This study indicated significant differences $(P<0.05)$ in albumin values in treated group $(17.00 \pm 1.17 \mathrm{~g} / \mathrm{L})$ in comparison to the control group $(21.60 \pm 1.14 \mathrm{~g} / \mathrm{L})$. OPs treated fish exhibited came to the surface of water, increased opercular movement, mucus secretion and progressively became lethargic. Most of them showed abnormal swimming movements including loss of orientation.

Histopathological, the kidney exhibited cloudy swelling and granular dystrophy. The boundaries between epithelial cells lining the basal membrane of kidney tubules were indistinct. Cell cytoplasm appeared cloudy, and in some cells it had a finely granular pattern. Some epithelial cells were separated from the kidney tubules and were found in tubular lumen. The changes in the hepatopancreas were more prominent. A high-grade granular dystrophy was observed. Hepatocytes were swelled and enlarged, and the boundaries among the cells were not distinct. The cytoplasm was finely granular and irregularly stained. At some sites, in single cells or cell clusters, the dystrophy has evolved into necrobiotic processes. As a result, the nuclei of affected cells exhibited a various stage of karyolysis or were completely lysed, and cell boundaries disappeared (Figure 1). Vascular hyperaemia was observed in the connective tissue stroma.

Table 1. Plasma concentrations of fibrinogen $(\mathrm{g} / \mathrm{L})$, ceruloplasmin $(\mathrm{mg} / \mathrm{L})$ and albumin $(\mathrm{g} / \mathrm{L})$ in control and pesticidetreated groups of common carp. Results are expressed as means \pm standard errors on the means (SEM).

\begin{tabular}{|l|c|c|}
\hline \multicolumn{1}{|c|}{ Parameters } & Control group & Suspect group \\
\hline Fibrinogen (g/L) & $1.23 \pm 0.05$ & $1.54 \pm 0.06^{*}$ \\
\hline Ceruloplasmin (mg/L) & $28.22 \pm 2.09$ & $28.87 \pm 2.49$ \\
\hline Albumin (g/L) & $21.60 \pm 1.14$ & $17.00 \pm 1.17^{*}$ \\
\hline
\end{tabular}

$*(P<0.05)$ indicate significant differences between suspect and control common carp. 

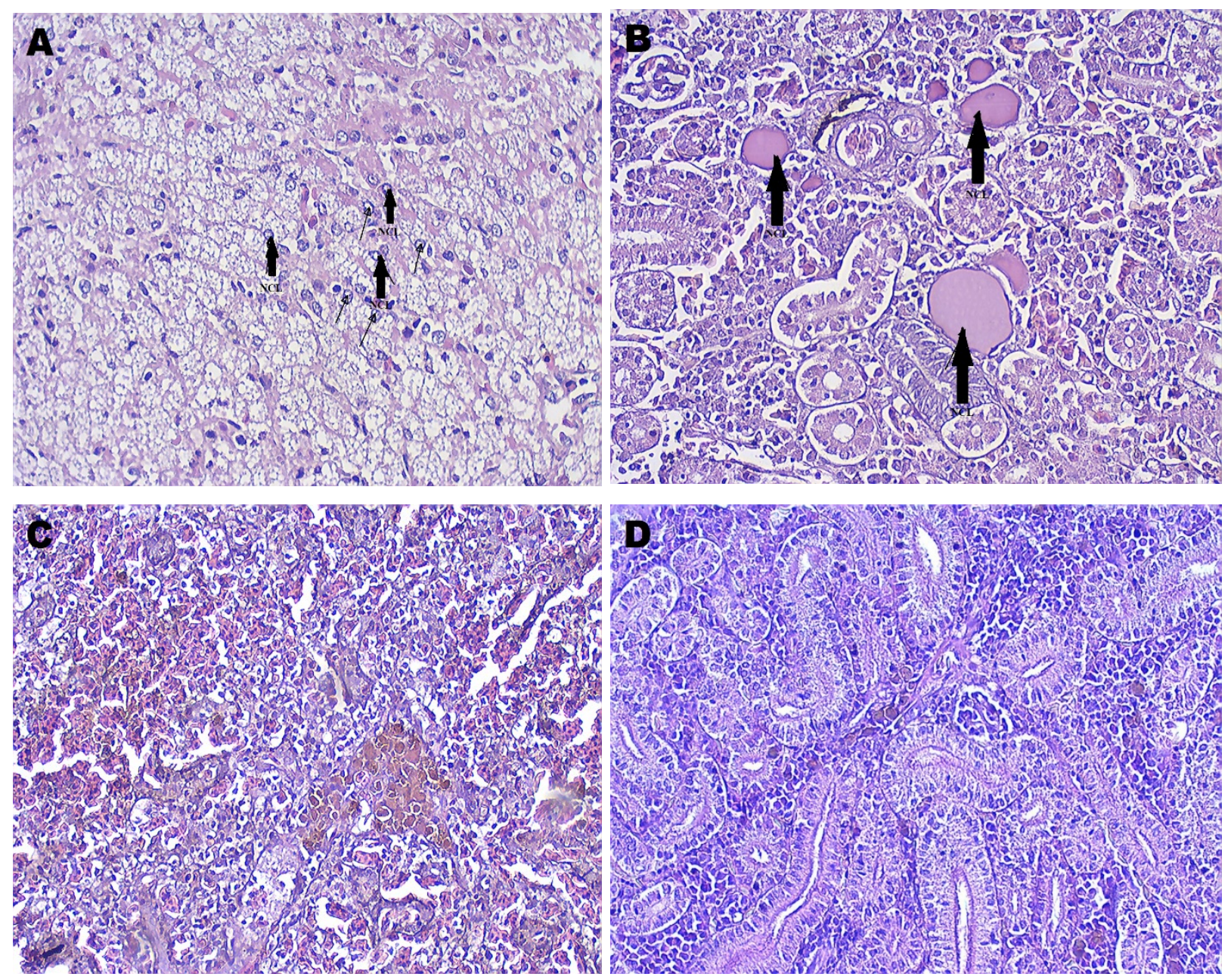

Figure 1. Photomicrograph of common carp: A. hepatopancreas treated with organophosphorus insecticides at the end of the month, showing nuclei cell lysis (NCL) and the structure of the organ was indistinct. B. kidney treated with organophosphorus insecticides showing nuclei cell lysis (NCL) and the structure of the organ was indistinct. $\mathbf{C}$ and D. hepatopancreas and kidney from control groups (H\&E magnification x20)

The use of pesticides are one of the most important factors contributing to the reduction in the fish population and other aquatic organisms. These pesticides are carried away by rains and floods to the large water resources and disturbs the physicochemical characteristics of water (Tripathi et al., 2011). The primary mechanism of action of OPs is as neurotoxic agents. They are effective inhibitors of AChE throught the interaction of the nucleophilic active site serine of the enzyme derivative. This enzyme is important for the neurological functioning of the sensory, integrative and neuromuscular systems in fish. Most insecticides have an effect on behavior of fish through influence on the nervous system and as a result, it can lead to disorders in the fish response to environmental stimuli. The effect of certain insecticides on the activity of AchE may also lead to a decreased mobility in fish (Banaee et al., 2013).
The acute-phase response (APR) is highly conserved in evolution. One of its characteristics is the alteration of the concentration of a variety of hepatocyte-derived APPs in blood. These proteins function as transport molecules, participate in tissue repair, mediate or inhibit inflammatory processes, and are part of the mechanism that controls homeostasis (Wang et al., 2007).

The mechanism of the APR and of induction of APP synthesis in fish has not been completely investigated. The fishes have limited APP production in the liver in response to inflammatory stimuli compared to APR in mammals. This agrees with other investigations on ectotherms such as plaice, channel catfish, and fresh water murrel, which react with weak or restricted inducible APP production (Simko, 1998). However, since there is evidence that some major acute phase cytokines and their receptors are evolutionarily 
highly conserved (Aoki et al., 2008) it is likely that the basic signalling mechanisms of the APR in fish are similar to those described in mammals. Several cytokine homologues, namely IL-1 $\beta$, IL-10, tumor necrosis factor (TNF $\alpha$ and $\beta$ ) have been cloned in fish species (including carps). Expression of IL-8 has been demonstrated in various teleost species e.g., rainbow trout, common carp, catfish, pink salmon, haddock, in response to inflammatory stimuli (Whyte, 2007). TNF expression studies, have demonstrated that TNFa mRNA expression and regulation in trout, carp and flounder is similar to that observed in mammals following similar activation kinetics. Two TNFs ( $\alpha$ and $\beta$ ) are present in mammals, and both the TNF $\alpha$-like gene has been cloned and analyzed in number of fish species including carp but seems that TNF $\alpha$ have more prevalent role in teleosts. Some studies of fishes (trout, carp, catfish, turbot, and sea bream) suggested that TNF- $\alpha$ and $-\beta$ are important activators of macrophages (Uribe et al., 2011).

In mammals, nonspecific response is performed predominantly of cytotoxic cells, known as natural killer cells. Nevertheless, the nonspecific cytotoxic cells of catfish are morphologically distinct from the large granular lymphocytes of mammals; they are suggested to be functionally similar. Also, these cells are agranular, small lymphocytes that are commonly found in lymphoid tissues (kidney and spleen), but are rarely found in the blood. Nonspecific cytotoxic cells have shown activity in other fish species, including common carp, rainbow trout, damsel fish and tilapia.

The studies in this manuscript were focused on investigating and comparing quantitative changes induced by non-inflammatory stimuli in plasma proteins (Fib, $\mathrm{Cp}, \mathrm{Alb}$ ) of common carp. Teleost fishes may be good indicators of contamination by pollutants because their biochemical responses are quite similar to those found in mammals (Banaee et al., 2008). Some researchers selected in advance some of the APPs and measurement their quantities in blood samples taken from control and experimental fish (trout, salmon, carp, catfish, plaice, murrel and tilapia). These investigators made it possible to understand that in elasmobranchs and teleosts are present homologs of some known APPs and concentrations of some of them increase in response to inflammatory stimuli. The changes in the concentrations of APPs are due largely to changes in their production by hepatocytes (Gabay and Kushner, 1999). As in animals, hepatocytes are the prime source of APP in fish (Bayne and Gerick, 2001).

Measurement of $\mathrm{Cp}$ which is nonspecific immunity parameter probably can be used as bio indicator of the health status of the fish. Yıldız and Ergönül (2010) reported that Cp values decreased after formalin exposure both in sea bream and sea bass and did not return to control values within $48 \mathrm{~h}$ recovery. In our study, Cp levels did not show change either in control group or in suspected fishes. The reduction may be the result of the defense mechanism of the host cell against an increased oxidation caused by the inflammatory stimuli. According Dunier et al. (1991) some blood parameters of nonspecific immunity (ceruloplasmine, lysozyme, hemagglutinins) were slightly affected by organophosphorus insecticide which are used in aquaculture to eliminate fish ectoparasites. Mikulikova et al. (2013) investigated the effect of herbicides on Cp levels in common carp and their research show that ceruloplasmin activity was not affected by the exposure.

In our study was not observed rising of concentrations of $\mathrm{Cp}$. The interesting is that in healthy common carp the levels were $28.22 \pm 2.09 \mathrm{mg} / \mathrm{L}$ and these values were the same as the group exposed to the treatment with pesticide -28.87 $\pm 2.49 \mathrm{mg} / \mathrm{L}$. These results suggest that $\mathrm{Cp}$ should not be used to evaluate the APR in common carp after short-term exposure to spraying with pesticides.

The concentrations of fibrinogen in common carp are between 2.0-2.6 g/L (Feeney and Brown, 1974). They are within the expected normal range for humans and domestic animals (2-4.5 g/L). In our study we observed that Fib concentrations in common carp were $1.23 \pm 0.05 \mathrm{~g} / \mathrm{L}$

Usually, the structure of acute-phase proteins and acutephase responses are similar in all species, having universal character in animal kingdom (Tirziu, 2009) but only a few inducible APPs were detected in the trout plasma and their degree of inducibility appears to be much lower than that of manmalian APPs (Simko, 1998). It could be that teleosts require longer periods for APP production after an inflammatory stimuli. Thus, this indicates that salmonids do not exhibit the same degree of acute phase protein response as seen in mammals (Simko, 1998). Magnadottir et al. (2011) showed a relatively slow humoral and cellular response to APR induction (by using the turpentine injection) in Atlantic cod, as well as slightly reduced serum protein level and little effect on the pentraxins.

In mammals, hepatic expression and plasma concentrations of haptoglobin, $\alpha 1$-acid glycoprotein, antitrypsin, fibnnogen and pentraxins increase along with many others during the APR (Gruys et al., 1998). By comparison, plasma changes in corresponding proteins do not change in fish to a degree observed in mammals, suggesting that the acute phase protein response of ectotherrnic vertebrates is limited (Simko, 
1998). However, it would seem that hepatic protein induction responses in fish are more limited than in mammals.

Changes in the concentration of serum protein, albumin and globulin have been used as indicators of stress response in fish (Sala-Rabanal et al., 2003). In the present study, albumin concentration decreased in the pesticide-treated fish which show that the metabolism of albumin was probably affected. Mikulikova et al. (2013) reported that Alb levels reflected to the exposure to pesticides with delay. They observed a reduction in albumin values in common carp. According them this parameter was influenced although it was not evident at the total protein levels. Reducing the plasma concentration of negative APP is probably caused by a preferential synthesis in liver of positive APPs which are important components of systemic defence mechanisms (Gruts et al., 1998).

Ramesh and Saravanan (2008) observed that in the pesticide treated fish, protein levels decreased. According to Vani et al. (2012), in Indian carp exposed to sub-lethal dose of cypermethrin (a synthetic pyrethroid) there is reduction of Alb levels (from $20.9 \mathrm{~g} / \mathrm{L}$ - controls to $10.3 \mathrm{~g} / \mathrm{L}$ for suspect group). They suggest that this may be attributed to the stress mediated mobilization of these compounds to satisfy the growing energy demand from fish to cope with a state where there is presence of toxics substances. Another possible reason for the lowered amount of albumin may be a decreased albumin synthesis in the hepatocytes. In the present study, similar findings have been observed in fishes. Our results showed a significant decrease in values of Alb compared to the control - concentrations reduced from $21.6 \mathrm{~g} / \mathrm{L}$ to $17 \mathrm{~g} / \mathrm{L}$. The control values in our study were close to the control date reported by Vani et al. (2012) (20.9 g/L) and near to the levels detected by Koynarski et., (2018) which showed that the reference range for Alb in cyprinids are between 5.3 and 22 $\mathrm{g} / \mathrm{L}$. In another study (Kopp et al., 2011) has examined the influence of cyanobacterial toxins on albumin levels of the common carp and have revealed that this parameter is not significantly different from the control group and has only a slight decrease. Lower levels may indicate diminished liver activity, but the decline in values may be caused by other factors.

Fishes exposed to insecticides showed abnormal behavior changes like swimming near the water surface with delayed movements, lethargic and erratic swimming, loss of navigability, loss of equilibrium etc. Similar changes in the behavior were observed by Banaee et al. (2013).

Histopathological analysis reported important alterations in liver, including changes in nuclear shape, morphological derangement and necrosis. Similar histopathological changes were observed in the liver tissue of carp, tilapia and catfish exposed of different insecticides (Banaee, 2013).

\section{Conclusion}

Collectively, these findings suggest that the carp do not exhibit a strong APP synthesis during the early stages of an APR after spraying with organophosphorus insecticides. The concentrations of fibrinogen are not significantly increase as well as the levels of ceruloplasmin remained unchanged. The possibility remains that there might be limited early change or that responses may be delayed beyond the period of examination. Likewise, it remains possible that carps might have an acute phase protein expression response to more powerful inflammatory stimuli than the organophosphorus pesticides administration examined in this study.

\section{Compliance with Ethical Standard}

Conflict of interests: The authors declare that for this article they have no actual, potential or perceived conflict of interests.

Ethics committee approval: All procedures were performed with clinical purposes in this type of study involving fish were in accordance Law on Veterinary and Medical Activities and National Animal Welfare Act, thus ethical approval was not required.

Financial disclosure: This work was supported by Scientific Grant No 06/14 from the Trakia University, Bulgaria.

\section{References}

Andreeva, A. (2010). Structure of fish serum albumins. Journal of Evolutionary Biochemistry and Physiology, 46(2), 135-144.

Aoki, T., Takano, T., Santos, M., Kondo, M., Hirono, I. (2008). Molecular innate immunity in Teleost fish: Review and future perspectives. Proceeding of the $5^{\text {th }}$ World Fisheries Congress, Yokohama, Japan, 263276.

Banaee, M., Mirvagefei, A., Rafei, G., Majazi Amiri, B. (2008). Effect of sub-lethal Diazinon concentrations on blood plasma biochemistry. International Journal of Environmental Research, 2(2), 189-198.

Banaee, M., Sureda, A., Mirvagefei, A., Ahmadi, K. (2013). Biochemical and histological changes in the liver tissue of rainbow trout (Oncorhynchus mykiss) exposed to sub-lethal concentrations of diazinon. Fish Physiology and Biochemistry, 39(3), 489-501.

Banaee, M. (2013). Physiological dysfunction in fish after insecticides exposure. In S. Trdan (Ed.), Insecticides Development of safer and more effective technologies 
(p. 103-142). Rijeka, CRO: InTech Press Inc. ISBN 978-953-51-0958-7.

Bestujeva, S., Kolb V. (1982). Determination of the activity of ceruloplasmin in the blood serum by the method of Revin. In V. Kolb \& V. Kamishnikov (Eds.), Practical book in clinical chemistry, $2^{\text {nd }}$ edition, (p. 290-291). Minsk, Belarus.

Bayne, C., Gerwick, L. (2001). The acute phase response and innate immunity of fish. Developmental and Comparative Immunology, 25(8-9), 725-743.

Ceron, J., Eckersall, P., Martinez-Subiela, S. (2005). Acute phase proteins in dogs and cats: current knowledge and future perspectives. Veterinary Clinical Pathology, 34(2), 85-99.

Cray, C. (2013). Biomarkers of inflammation in exotic pets. Journal of Exotic Pet Medicine, 22(3), 245-250.

Di Giulio, R., Meyer, N. (2008). Reactive oxygen species and oxidative stress. In R. Di Giulio \& D. Hintin (Eds.), The toxicology of fishes (p. 273-327). Boca Raton, USA: CRC Press, ISBN 978-041-52-4868-6.

Dunier, M., Siwicki, A., Demael, A. (1991). Effects of organophosphorus insecticides: Effects of trichlorfon and dichlorvos on the immune response of carp (Cyprinus carpio). Ecotoxicology and Environmental Safety, 22(1), 79-87.

Feeney, R., Brown, W. (1974). Plasma proteins in fishes. In M. Florkin \& B. Scheer (Eds.), Chemical Zoology. Volume 8. Deuterostomians, Cyclostomes and Fishes (p. 307-329). London, UK: Academy Press, ISBN 978012-2610-38-7.

Gabay, C., Kushner, I. (1999). Acute-phase proteins and other systemic responses to inflammation. The New England Journal of Medicine, 340(6), 448-454.

Gruys, E., Toussaint, M., Landman, W., Tivapasi, M., Chamanza, R., Van Veen, L. (1998). Infection, inflammations and stress inhibit growth. Mechanisms and non specific assesment of the processes by acute phase. In T. Wensing (Eds.), Production diseases proteins in farm animals (p. 72-88). Amsterdam, Netherland: Wageningen Press, ISBN 90-74134-60-2.
Karami-Mohajeri, S., Abdollahi, M. (2011). Toxic effects of organophosphate, carbamate, and organochlorine pesticides on cellular metabolism of lipids, proteins, and carbohydrates: A comprehensive review. Human and Experimental Toxicology, 30(9), 1119-1140.

Koynarski, T., Zapryanova, D., Atanasoff, A., Nikolov, G., Hristova, D., Secer, F.S. (2018). Seasonal fluctuations of innate immunity among three phylogenetically diverse fish. Fresenius Environmental Bulletin, 27(12), 8529-8535.

Kopp, R., Palikova, M., Mares, J., Navratil, S., Kubicek, Z., Zikova, A. (2011). Haematological indices are modulated in juvenile carp (Cyprinus carpio) exposed to microcystins produced by cyanobacterial water bloom. Journal of Fish Diseases, 34(2), 103-114.

Magnadottir, B., Audunsdottir, S, Bragason, B, Gisladottir, Z., Jonsson, S, Gudmundsdottir, S (2011). The acute phase response of Atlantic cod (Gadus morhua) humoral and cellular response. Fish and Shellfish Immunology, 30(4-5), 1124-1130.

Mikulikova, I., Modra, H., Blahova, J., Kruzikova, K., Marsalek, P., Bedanova, I., Svobodova, Z. (2013). Recovery ability of common carp (Cyprinus carpio) after a short-term exposure to terbuthylazine. Polish Journal of Veterinary Sciences, 16(1), 17-23.

Nagaraju, B., Rathnamma, V. (2013). Effect of profenofos an organophosphate on protein levels in some tissues of fresh water fish Labeo rohita (Hamilton). International Journal of Pharmacy and Pharmaceutical Sciences, 5(1), 276-279.

Ramesh, M., Saravanan, M. (2008). Haematological and biochemical responses in a freshwater fish Cyprinus carpio exposed to chlorpyrifos. International Journal of Integrative Biology, 3(1), 80-83.

Sala-Rabanal, M., Sanchez, J., Ibarz, A., Fernandez-Borras, J., Blasco, J., Gallardo, M. (2003). Effects of low temperatures and fasting on hematology and plasma composition of gilthead sea bream (Sparus aurata). Fish Physiology and Biochemistry, 29(2), 105-115.

Simko, E. (1998). Acute phase response to inflammation in salmonid fishes. PhD Thesis: University of Guelph, Guelph. 
Tirziu, E. (2009). Acute-phase proteins in immune response. Lucrări Ştiinţifice Medicină Veterinară, 42(1), 329339.

Tothova, C., Nagy, O., Seidel, H., Kovac, G. (2011). Acute phase proteins as markers of diseases in farm animals. In F. Veas (Eds.), Acute phase proteins as markers of diseases in farm animals, acute phase proteins as early non-specific biomarkers of human and veterinary diseases (p. 231-258). Rijeka, CRO: InTech Press Inc. ISBN 978-953-307-873-1.

Tripathi, V., Singh, K. Mishra, N. Gupta, R. (2011). Evaluation of biochemical changes induced by lindane and chlorpyrifos in a freshwater catfish (Clarias batrachus) during spawning phase. Journal of Experimental Zoology, India, 14(1), 587-589.

Uribe, C., Folch, H., Enriquez, R., Moran, G. (2011). Innate and adaptive immunity in teleost fish: A review. Veterinarni Medicina, 56(10), 486-503.

Vani, T., Saharan, N., Roy, S., Ritesh Ranjan, A., Pal, G.,
Siddaiah, M., Kumar, R. (2012). Alteration in haematological and biochemical parameters of Catla catla exposed to sub-lethal concentration of cypermethrin. Fish Physiology and Biochemistry, 38(6), 1577-1584.

Wang, J., Wei, Y., Li, X., Xu, M., Dai, J. (2007). Identification of differentially expressed genes from contaminant and thermal exposed goldfish (Carassius auratus) in Gaobeidian Lake in Beijing, China. Ecotoxicology, 16(7), 525-532.

Whyte, S. (2007). The innate immune response of finfish A review of current knowledge. Fish and Shellfish Immunology, 23(6), 1127-1151.

Yıldı, H., Ergönül, M. (2010). Is prophylactic formalin exposure a stress source for gilthead sea bream (Sparus aurata) and sea bass (Dicentrarchus labrax)? Veterinary Journal of Ankara University, 57(2), 113-118.

Yonar, M., Saglam, N., Ispir, U. (2010). Effect of sulfamerazine on plasma ceruloplasmin levels in rinbow trout (Onchorhynchus mykiss). Turkish Journal of Science \& Technology. 5(2), 79-84. 